Sādhanā Vol. 28, Part 5, October 2003, pp. 933-944. @ Printed in India

\title{
A comparative machining study of diamond-coated tools made by plasma torch, microwave, and hot filament techniques
}

\author{
C E BAUER, A INSPEKTOR and E J OLES \\ Kennametal Inc., Corporate Technology Center, Latrobe, PA 15650, USA \\ e-mail: ed.oles@kennametal.com
}

\begin{abstract}
An effective metal-cutting tool is usually a combination of a hard coating and a tough substrate. The successful deposition of diamond outside its thermodynamic stability range has stimulated the development of a new class of cutting tools: those with diamond-coated inserts of any desired style and edge geometry. The successful implementation of diamond coatings also expedited similar research in the deposition of cubic boron nitride. This paper presents superhard coating tools, with emphasis on diamond-coated WC-Co tools, the corresponding deposition of technologies and the foreseen metal-cutting applications.
\end{abstract}

Keywords. Diamond-coated tools; metal-cutting tools; superhard materials.

\section{Introduction}

In recent years we have witnessed major development in the field of hard coatings: the successful deposition of diamond, the hardest material in nature, outside its thermodynamic stability range (Spitsyn et al 1981; Matsumoto et al 1982; Yarbrough et al 1990). The deposition of diamond has stimulated the development of a new class of cutting tools, namely diamondcoated WC-Co alloys and $\mathrm{SI}_{3} \mathrm{~N}_{4}$ based inserts (Kikuchi 1991; Lux \& Haubner 1989) and has expedited similar research in the second hardest material, cubic boron nitride (Murukawa \& Watanable 1990; Ikeda 1991; Sueda 1993). This paper discusses superhard coated tools, the corresponding deposition technologies and the foreseeable metal cutting applications.

\section{Superhard materials and tools}

Superhard materials are materials that are significantly harder than any other compounds, and thus they can shape, scratch or indent any other object. The minimum hardness of a superhard material is set, often arbitrarily at a Knoop hardness value of $40 \mathrm{GPa}$ or greater. Diamond and cubic boron nitride $(\mathrm{cBN})$, the high-temperature high-pressure cubic phases of carbon and boron nitride, are the prominent superhard materials. Among other likely materials are boron carbide with high hot hardness, boron suboxides which are boron-rich phases of boron oxide (Badzian 1988), polycrystalline superlattice coatings with alternating nano-layers of compatible materials such as TiN/NbN (Chu 1992) and the hypothetical $\beta$-carbon nitride (Liu 1990), with a postulated hardness greater than that of diamond. 
Superhard tools are tools made of superhard components. At present these are the polycrystalline diamond (PCD) and the polycrystalline cubic boron nitride (PCBN) tools. PCBN tools are used mostly for machining hard ferrous materials whereas PCD tools are used for non-ferrous alloys and composites that are difficult to cut. The cutting edge of a polycrystalline tool is a superhard tip brazed onto a carbide insert. The tip is cut from a blank made of micrometre sized diamond or cBN crystals intergrown with a suitable metallic or ceramic hinder and bonded onto a cemented carbide support. The diamond and the $\mathrm{cBN}$ crystals and the blanks are synthesized and sintered at high pressure high temperature (HP-HT) conditions (about $50 \mathrm{kbar}$ and about $1500^{\circ} \mathrm{C}$ ).

Owing to the high costs involved in HP-HT manufacturing and in the finishing of the tool. PCD and the PCBN tools are very expensive. The tools are also usually tipped and limited to a relatively few styles with planar geometry. Nonetheless, PCD and PCBN tools are still the best and sometimes the only tools suitable for economical machining of difficult-to-cut materials. The superhard tools are the fastest growing segment of the cutting tool market. The worldwide market for diamond and cBN materials has been estimated at $\$ 3.65$ billion in 1991 (Anon 1991). In the past few years the annual volume consumption of diamond worldwide has increased by $11 \%-12 \%$ with $4 \%-5 \%$ being used in cutting tools. GE Superabrasives and DeBeers are the major manufacturers of superhard blanks with about $90 \%$ of the worldwide PCD and PCBN tip market. Other major producers of superhard blanks are Sumitomo, Japan and Megadiamond, USA.

The low pressure deposition of diamond begins a new era in the superhard tools market, the introduction of "regular" carbide tools with conforming layers of diamond coatings. Without the limitation of the HP-HT process a diamond-coated tool can be manufactured in essentially any style and with any (tailor-made) geometry of the cutting edge. As the entirely functional surface of the tool is coated, many of the present depth-of-cut limitations in the machining process are eliminated. Besides, in the absence of a binder, the new tool may outperform the sintered material in some applications as pure diamond is harder and more chemically inert than the sintered blank. It is anticipated that the improved geometry of coated tools will translate into improved metal-cutting performance and will enable high-speed machining of difficult-to-cut materials. Accordingly, coated tools will lower machining cost per cutting edge with increased productivity. Superhard-coated tools will enable production of better designed higher quality parts at lower costs. It is likely that the new tools will open up new markets and new applications in machining hard and wear-resistant materials.

\section{Diamond-coated tools}

The first diamond-coated tools in the market were $\mathrm{Si}_{3} \mathrm{~N}_{4}$ based inserts (e.g. Idemitsu 1991). Diamond-coated WC-Co tools have been successfully prepared only after understanding the carbon-cobalt interaction and finding better ways to guarantee the adhesion of the diamond film. Accordingly, the deposition of diamond on cemented WC-Co inserts is a two-phase process. The first step is the preparation of the substrate to assure good bonding between the diamond and the carbide surface. The second step is the diamond deposition.

\subsection{The diamond-carbide interface}

Adhesion is a complex function of intrinsic and extrinsic parameters including nucleation density, compatibility of thermal expansion coefficients, and surface preparation. In the diamondcarbide case the two major factors are: (1) mismatch of thermal expansion coefficients and 


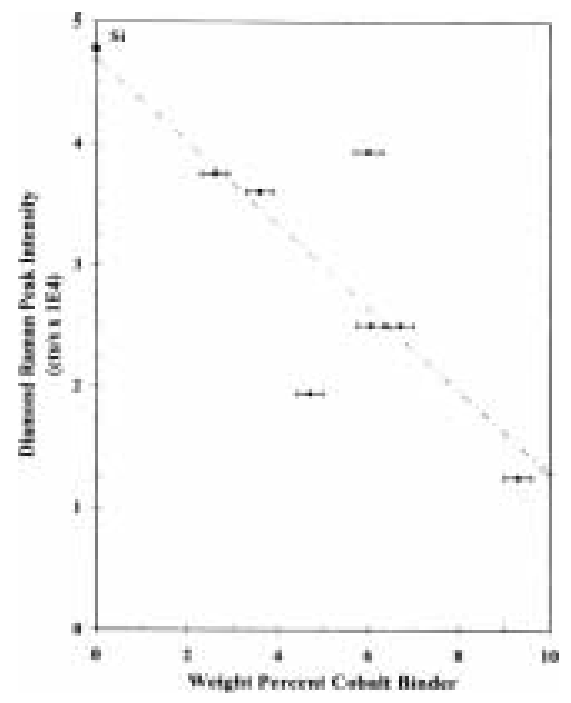

Figure 1. Intensity of the $1333 \mathrm{~cm}^{-1}$ Raman peak of diamond function of cobalt content in the WC-Co substrate.

ensuing large thermal stresses at the diamond-carbide interface (Kuo et al 1990), and (2) composition and properties of the diamond-carbide interface. Without strong bonding to the substrate the coating will not endure the shearing force in machining processes and will flake.

The surface of an as-vacuum-sintered cemented carbide alloy consists of tungsten carbide crystals and cobalt. The cobalt is present mostly between the carbide crystals but it also covers some of the grains owing to the excellent wetting properties of Co and WC. In addition, the preparation of the carbide tool normally requires that the as-sintered tool be ground for exact dimensional control. The grinding process smears the cobalt binder alloy over the surface of the sintered cemented carbide tool. Under these circumstances, the adhesive strength of the diamond coatings on carbide inserts is largely determined by the interaction between the carbon and a thin layer of cobalt that is present on the surface of the tool (Lux \& Haubner 1989).

The presence of cobalt is harmful to diamond deposition on WC-Co tools (McCune et al 1989; Soderberg 1990). The cobalt binder suppresses the diamond nucleation and accelerates the formation of graphite instead (Murukawa et al 1988; Soderberg 1990). The amount of cobalt in the carbide substrate also adversely affects the "Raman quality", the facet size and the roughness of a diamond film (Park et al 1993). Similar correlation between the amount of cobalt in the substrate and the "Raman quality" of a microwave plasma film is shown in figure 1. Under typical deposition conditions carbon exhibits a large solubility and diffusivity in cobalt. The dissolution and diffusion of carbon into the cobalt first extends the incubation period of diamond nucleation. Then the dissolved carbon reprecipitates as graphite, the thermodynamically stable carbon phase. As is shown schematically in figure 2, the resulting accumulation of graphite at the diamond-carbide interface breaks the diamondcarbide bonding and degrades the "quality" of the diamond film. The rate-determining step of the cobalt-catalysed formation of graphite and accumulation at the diamond carbide interface is the temperature dependent migration and dissolution of carbon atoms in cobalt.

To achieve a good bond between the diamond film and the carbide substrate, it is essential to limit the carbon cobalt interaction. The corresponding reported experimental approaches include the use of surface etching, surface treatments and intermediate coatings. Chemical and electrochemical etching of cobalt are widely used to reduce the amount of cobalt at the 


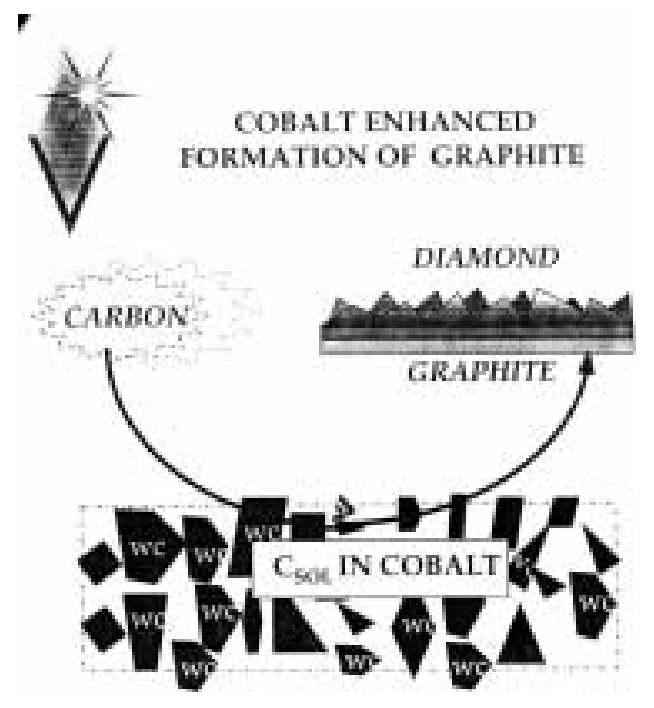

Figure 2. Cobalt-enhanced formation of graphite during diamond deposition.

diamond-insert interface (e.g. Suzuki et al 1986; Saito et al 1991). The reported etching procedures include the use of $\mathrm{H}_{2} \mathrm{O}_{2}: \mathrm{H}_{2} \mathrm{SO}_{4}=9$ : 1 (Park et al 1993), $\mathrm{HNO}_{3}$ (Nesladek et al 1993) and other solvents. Surface treatments are described by other researchers like Saijo et al (1990) who have used decarburised hot pressed cobalt free WC substrates with recrystallised WC grains. Saito et al (1993) described heat treatment of the insert to form a solid solution enriched and cobalt-depleted layer on its surface. The deposition of an intermediate layer prior to formation of the diamond film serves two purposes: (1) formation of a diffusion barrier between the cobalt and the diamond film; (2) to relieve residual stresses at the diamondcarbide interface. Potentially adequate materials are silicon and some transition metals such as Ta, Hf, Nb and W. Nesladek et al (1993) reported a stress relief three-layered structure of refractory metal layers as diamond bonding layers and an intermediate silver as a stress relaxing layer.

Good diamond-carbide bonding is a key factor in the development of coated tools and is the most sensitive criterion in metal-cutting applications. A typical critical load is $60 \mathrm{~kg}$ or more for coatings in excess of $10 \mu \mathrm{m}$ thickness (Brale indentation test, Jindal et al 1987). However, laboratory adhesion tests can only provide preliminary and comparative data and field test performance in real life applications is the actual acceptance criterion in practice.

\subsection{Diamond deposition}

Elementary processes in diamond deposition are: (1) dissociation of the hydrocarbon source and formation of the diamond precursors; (2) transport of the active spades to the surface, and (3) diamond nucleation and growth. In the process the diamond phase is in continuous competition with the thermodynamically layered graphite phase A good quality film is formed in the presence of the copious amounts of atomic hydrogen needed to stabilise the $s p^{3}$ diamond bonding and to reduce the amount of graphite in the film. Addition of oxygen (elemental or as oxygen-hydrocarbon compounds) to the feed gas can help to increase the hydrocarbon dissociation rate, raise the concentration of atomic hydrogen in the system and improve the overall quality of the diamond film (Inspektor et al 1989). 
The adequate commercial diamond deposition systems are microwave plasma, hot filament and plasma torch.

The plasma-assisted deposition system employs a microwave power source to produce a glow discharge plasma. The substrate is placed within the non-equilibrium glow discharge region. Typical deposition conditions are mixtures of $0.5 \%-5 \%$ methane in hydrogen with or without oxygen addition. The deposition rates are on the order of $2-3 \mu \mathrm{m} \mathrm{h}^{-1}$ and the substrate temperature is in the range $700-1000^{\circ} \mathrm{C}$ depending on power dissipation and the nature of the substrate (Nesladek et al 1993).

Hot filament arrays for diamond deposition use wires (filaments) made of refractory metals such as tungsten, tantalum and rhenium. The filaments are heated electrically to $2000-2500^{\circ} \mathrm{C}$ to produce the necessary amounts of atomic hydrogen and diamond precursors. Typical conditions arc mixtures of $0.5-1.5 \%$ methane in hydrogen and the deposition rate is on the order of $0.5-1.5 \mu \mathrm{m} \mathrm{h}^{-1}$. The underlying principles, experimental conditions and relevant consideration for up-scaling the hot-filament array are listed in a recent review (Haubner \& Lux 1993).

The plasma torch involves the use of d.c and r.f. plasma jets. It is a thermal plasma technique with gas temperatures in the range $5000-8000^{\circ} \mathrm{C}$. The accelerated dissociation of the gaseous precursors in the hot plasma enable extremely high deposition rates. A typical gas feed mixture is $1500 \mathrm{sccm}$ hydrogen and $60 \mathrm{sccm}$ methane $(0.75 \%$ methane in hydrogen $)$ with a deposition rate of $400 \mu \mathrm{m} \mathrm{h}^{-1}$. The temperature of the molybdenum substrate in the reported conditions was about $1000^{\circ} \mathrm{C}$ (Ohtake et al 1991).

As mentioned, the cobalt-catalysed accumulation of graphite at the diamond-carbide interface is a temperature dependent process. Consequently, an effective coating on WC-Co tools is carried out at a low substrate temperature. The low temperature deposition approach also combines well with the cobalt depleting methods, where the low temperature will reduce the likelihood of cobalt migration back to the surface. Nevertheless, a low temperature process carries the disadvantage of low deposition rate and consequently higher costs In practice, all the leading deposition methods are suited for the low temperature process The question remains which, if any, is the method of choice for the production of diamond-coated WC-Co tools.

Development of adequate surface preparation techniques has enabled the deposition of adherent diamond films on WC-CO tools by all three deposition models and has allowed completion of the required comparative metal-cutting test. The test materials included WC-Co inserts diamond-coated by microwave plasma, hot filament and plasma torch processes, and conventional PCD ( $25 \mu \mathrm{m}$ diamond particle size). The tested inserts were all coated to the same nominal thickness. The inserts were tested in wet turning of hypereutectic A390 (Reynolds) aluminium-silicon alloy $(17.0 \% \mathrm{~S}-4.5 \% \mathrm{Cu}-0.6 \% \mathrm{Mg})$. The turning conditions were a cutting speed of $762 \mathrm{~m} \mathrm{~min}^{-1}$, feed rate of $0.127 \mathrm{~mm} \mathrm{rev}^{-1}, 0.635 \mathrm{~mm}$ depth of cut and lead angle of $15^{\circ}$ ' using SPGN 120308 inserts. In the test, each of the coating methods was represented by inserts from two different coating systems and experimental conditions. None of the coatings flaked and with abrasive wear as the only failure mechanism the comparative tests were conducted until a wear land of $0.254 \mathrm{~mm}$ was measured on the flank of the tools. In addition, the roughness of the workpiece was measured and comparison of the coating methods in terms of the surface finish generated has been conducted.

The performance of the different diamond-coated tools are presented in figures 3 and 4 . Figure 3 compares the flank wear of hot filament (HF), microwave plasma (MW) and plasma torch (PT) coated tools. The wear rates of the various tools are described by the slope of flank wear vs. cutting time. The slopes are essentially equal suggesting that at present, the "metal-cutting ability" of diamond films from the three different sources is similar. The same conclusion can also be drawn by comparing the relative tool life of the coated tools, i.e. time 

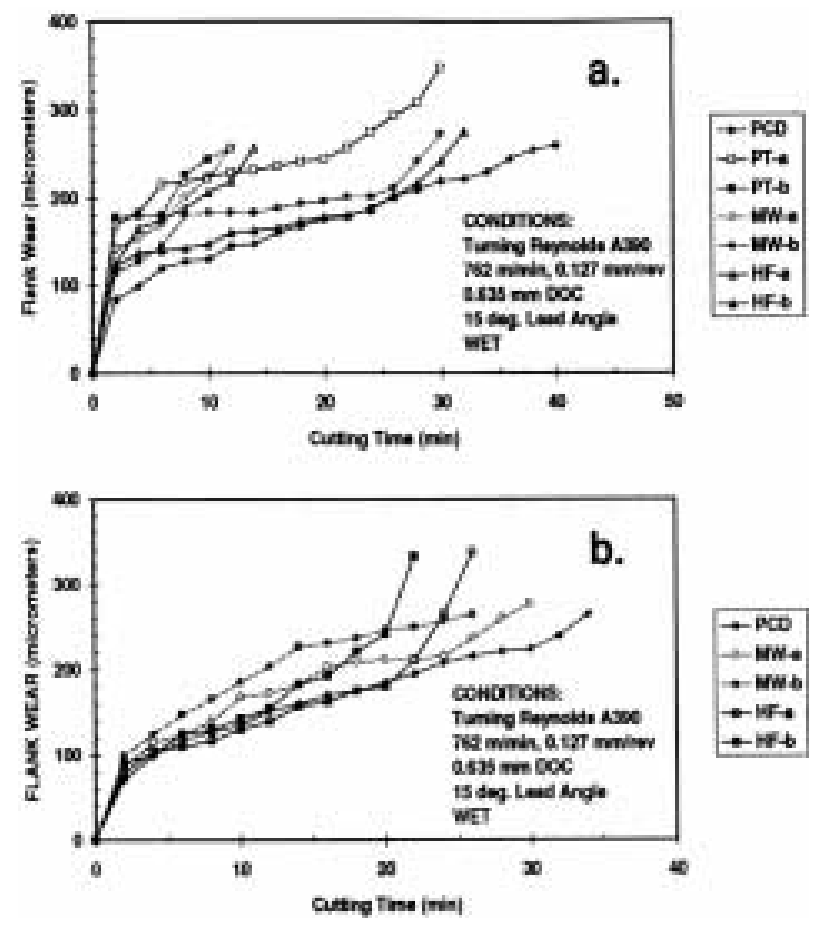

Figure 3. Two examples of flank wear as a function of cutting time in turning Reynolds A390. The figure compares the performances of plasma torch (PT), microwave (MW) and hot filament (HF) diamond-coated tools (two, $a$ and $b$, in each case) vs. polycrystalline diamond (PCD).

to reach the predetermined $0.254 \mathrm{~mm}$ wear land in the coated tool. The relative tool life of the coated inserts was compared with the tool life of PCD tools tested in parallel. The relative tool life of the tested inserts vs. PCD references are shown in figure 4 and the workpiece surface

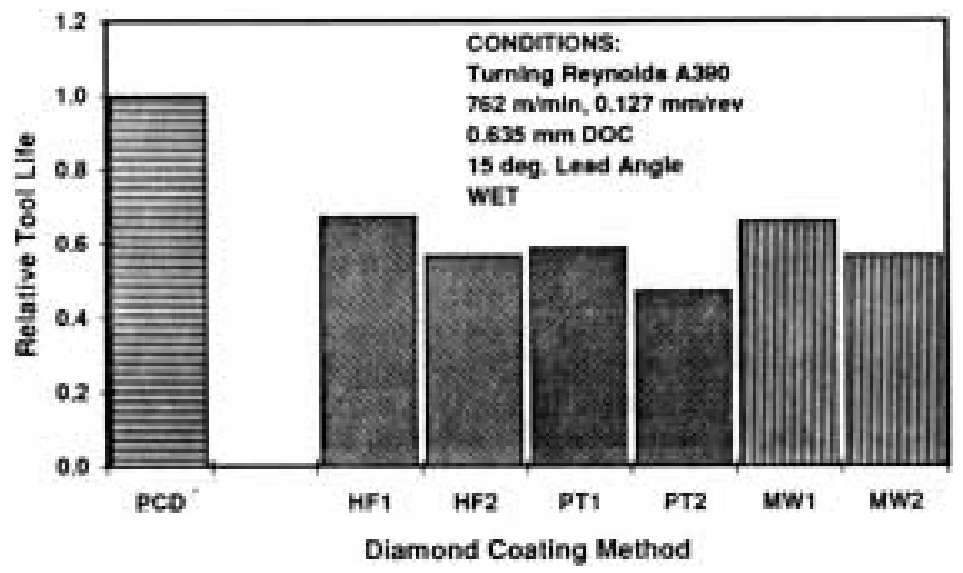

Figure 4. Performance of diamond-coated tools relative to polycrystalline diamond (PCD) in turning Reynolds A390. The performance is determined by the time it takes to develop a wear scar of $254 \mu \mathrm{m}$ and expressed relative to $\mathrm{PCD}=1$. The figure compares tools coated by hot filament $(\mathrm{HF})$, plasma torch (TC) and microwave (MW) techniques. Each technique is represented by two different sources/systems (1 and 2). 


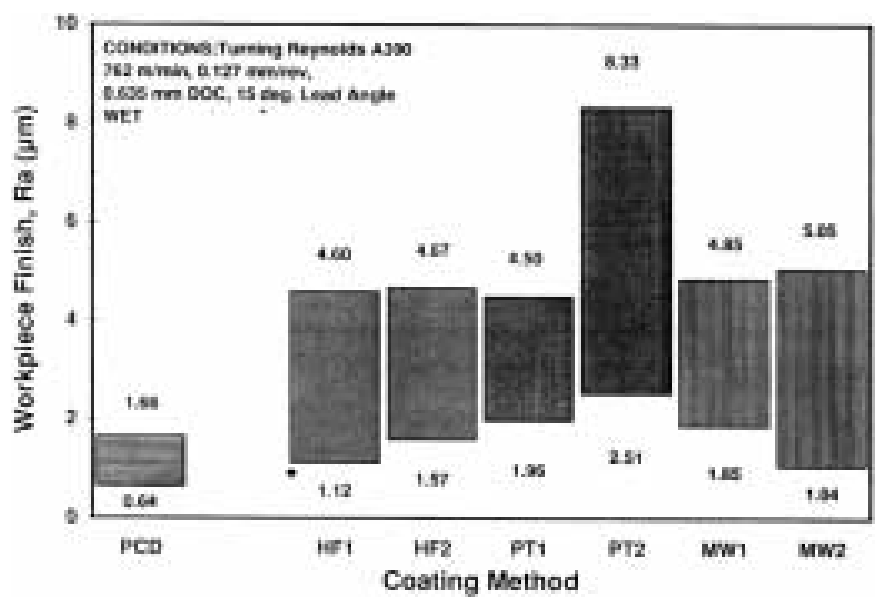

Figure 5. Surface finish generated by diamond-coated tools and polycrystalline diamond (PCD) in turning Reynolds A380. the figure compares tools coated by hot filament (HF), plasma torch (TC) and microwave (MW) techniques. Each technique is represented by two different sources/systems (1 and 2).

finishes generated are summarised in figure 5. In general, the diamond-coated tools provide rougher workpiece surfaces than PCD but, again, the values of surface finish generated by the three different coating methods are essentially in the same range.

It is concluded that at present the three leading deposition methods are equally suited for metal-cutting applications. However, full production will depend on several factors. These include capacity for large batches of high and uniform quality coated tools, high deposition rate and controllable and reproducible deposition conditions, and inexpensive, reliable and simple-to-operate equipment. The comparative test suggests that the only difference between the listed techniques is in the manufacturing costs of the diamond-coated tools.

\section{Cubic boron nitride coatings}

Boron nitride is a group III-V synthetic material. Its system of crystalline phases is analogous to that of carbon, with three corresponding crystallographic forms: (1) hBN with a hexagonal, graphitic structure, (2) cBN with a cubic, diamond structure and (3) wBN with a wurtzite, hexagonal-diamond structure. Cubic boron nitride $(\mathrm{cBN})$ is the HT-HP phase of boron nitride and a structural analogue of diamond. Accordingly it is the second hardest material available (up to $60 \mathrm{GPa}$ ). Many of the properties of $\mathrm{cBN}$ are similar to those of diamond, offering potential uses as a high band gap semiconductor material, in tribological applications and as a protective layer for optical devices.

Although the deposition of $\mathrm{cBN}$ is not a substrate sensitive process, formation of a cBN coated tool is still a two step operation. The reason for this is that the adhesion of cBN coatings is limited by high compressive stresses in the films. The film-substrate interface can be reinforced by the formation of an intermediate layer (as a single or as a multi-layer film (e.g. $\mathrm{Ti} / \mathrm{iBN} / \mathrm{cBN}$ Ikeda et al 1991). The cBN film is then deposited on top of the intermediate layer. Vapor phase deposition of $\mathrm{cBN}$ films has been attempted by many investigators using chemical vapour deposition (CVD) and physical vapour deposition (PVD) techniques. The literature consistently shows an advantage to the PVD methods. For example, Satou \& Fujimoto (1983) 
used electron beam evaporation of boron with $50 \mathrm{keV}$ nitrogen ion bombardment of the substrate to make cBN. Subsequently, different combinations of boron and ionised nitrogen have been used to make cBN. The boron can be obtained by electron beam evaporation (Murukawa et al 1991; Wada \& Yamashita 1992; Kester \& Messier 1992; Ikeda 1992), excimer laser ablation (Doll et al 1991), ion beam assisted sputtering (Shimokawa et al 1985) and r.f. diode sputtering (Goranchev et al 1987; Mieno \& Yoshida 1990). The ionised nitrogen was obtained by low (Kester \& Messier 1992; Anadoh et al 1988) and high (Murukawa et al 1991) energy ion beams, r.f. bias to the substrate with (Wada \& Yamashita 1992) and without magnetic fields, hollow cathode (Inagawa et al 1989) and microwave discharge.

The results indicate that the formation of $\mathrm{cBN}$ require high concentrations of elemental boron in the gas phase, an intense ion bombardment of the film, and the formation of an energetic plasma layer near the surface. Of particular interest are reports concerning ion assisted deposition (IAD) of $\mathrm{cBN}$. The IAD technique involves the use of energetic ion beam (nitrogen and argon) bombardment of a substrate which is simultaneously being coated with electron beam evaporated boron. Formation of the cubic phase will then depend on (1) the balance between the flux of nitrogen ions and the evaporated boron and (2) the energy of the impinging species on the surface. The impinging ions will mix the boron with the substrate material to improve the coating-substrate interface and will form the boron nitride compound.

\section{Application of superhard coated tools}

Diamond is the hardest material in nature, with Knoop hardness up to $100 \mathrm{GPa}$. It has a low friction coefficient, high thermal conductivity and a low thermal expansion coefficient. In spite of that, diamond is brittle and at elevated temperatures it chemically reacts with elements from groups IVa through VIla of the periodic table. The wear modes of diamond and $\mathrm{cBN}$ tools are combinations of oxidation, chemical reactions with the workpiece material, microfractures, and gross fractures. The oxidation of diamond becomes measurable at $600^{\circ} \mathrm{C}$ and progresses very rapidly at $1000^{\circ} \mathrm{C}$. Thus, diamond tools are limited to non-ferrous and non-metallic materials, as listed in table 1 . In contrast to the gaseous products $\left(\mathrm{CO}\right.$ and $\left.\mathrm{CO}_{2}\right)$ in diamonds, oxidation of cBN results in a formation of a boron oxide $\left(\mathrm{B}_{2} \mathrm{O}_{3}\right)$ layer which

Table 1. Materials suitable for diamond and cBN coating.

\begin{tabular}{|c|c|c|}
\hline \multicolumn{2}{|c|}{ Diamond tooling } & \multirow{2}{*}{$\frac{\mathrm{cBN} \text { tooling }}{\text { Metallic materials }}$} \\
\hline Metallic materials & Non-metallic materials & \\
\hline Aluminum, aluminium alloys & Alumina & $\mathrm{NiCr}$ cast iron. $\mathrm{Ni}$ \\
\hline Brass & Bakelite & Hard white/chill cast \\
\hline Bronze & & iron tool steel \\
\hline Copper, copper alloys & Carbon-graphite & Case hardened steel \\
\hline $\begin{array}{l}\text { Electroless, electrodeposited } \\
\text { nickel }\end{array}$ & Ceramics (green) & \\
\hline Lead alloys & Fibreglass-epoxy & Grey cast iron \\
\hline Gold alloys & & \\
\hline Magnesium alloys & Filled plastics & \\
\hline Silver, silver-aluminium alloys & Wood & Cobalt \\
\hline $\begin{array}{l}\text { Tungsten carbide-green zinc } \\
\text { alloys }\end{array}$ & $\begin{array}{l}\text { Reinforced polymers } \\
\text { Silicon carbide and nitride }\end{array}$ & $\begin{array}{l}\text { Nickel and iron based } \\
\text { hard alloys }\end{array}$ \\
\hline
\end{tabular}


Table 2. Mechanical and thermal properties of WC-Co and superhard materials.

\begin{tabular}{lccccc}
\hline Property & WC-Co & PCD & PCBN & Diamond & cBN \\
\hline Density $\left(\mathrm{g} \mathrm{cm}^{-3}\right)$ & $14 \cdot 70$ & $3 \cdot 43$ & $3 \cdot 12$ & 3.52 & 3.49 \\
Compressive strength $(\mathrm{GPa})$ & $4 \cdot 50$ & $4 \cdot 74$ & $3 \cdot 8$ & 8.58 & $4.15-5 \cdot 33$ \\
Fracture toughness $\left(\mathrm{MPa} \mathrm{m}{ }^{1 / 2}\right)$ & $10 \cdot 8$ & $6 \cdot 89$ & $10 \cdot 0$ & 3.4 & \\
Knoop hardness $(\mathrm{GPa})$ & 13 & 50 & 28 & $57-104$ & $44-60$ \\
Young's modulus $(\mathrm{GPa})$ & 620 & 925 & 680 & 1141 & \\
Poisson ratio & $0 \cdot 22$ & $0 \cdot 086$ & $0 \cdot 22$ & 0.070 & \\
Thermal expansion coefficient & $5 \cdot 0$ & $3 \cdot 8$ & 4.9 & $3 \cdot 5 \times 10^{-6}$ & $4.8 \times 10^{-6}$ \\
$\quad\left(\mathrm{~K}^{-1}\right)$ & & & & at $430^{\circ} \mathrm{C}$ & at $430^{\circ} \mathrm{C}$ \\
Thermal conductivity $\left(\mathrm{W} \mathrm{m}^{-1} \mathrm{~K}^{-1}\right)$ & 100 & 120 & 100 & $200-2000$ & $200-900$ \\
\hline
\end{tabular}

protect the tool from further attack. As a result, cubic boron nitride is chemically inert to hot iron, steel, and oxidizing environments. PCBN tools are used to machine hardened steels (HRC 50-65), high temperature alloys, grey cast iron and sintered ultra-fine powdered metals. Essential mechanical and thermal properties of PCD and PCBN tools, as well as of diamond and cBN crystals are summarised in table 2. (Oberg 1992; Rapoport 1985; Devries 1972). Some of the major applications of diamond and of cBN tools are listed below.

\subsection{Diamond tools}

The automotive industry is today the major user of diamond tools in machining components made of aluminium-silicon alloys, in particular the 300 series. Machinability of the light and wear resistant aluminium-silicon alloys is determined by the content as well as by the size and distribution of the silicon particles. The addition of silicon improves the casting properties of the alloy but impairs its machinability. Turning tests of the highly abrasive hypereutectic A390 alloy $(17.0 \% \mathrm{Si}-4.5 \% \mathrm{Cu}-0.6 \% \mathrm{Mg}$ ) as well as turning and milling of hypereutectic alloys (e.g. A380: $8.5 \% \mathrm{Si}-3.5 \% \mathrm{Cu}$ ) have shown equivalent performance between PCD and diamondcoated tools (Bauer et al 1994).

Machining metal-matrix composites (MMC) is another major application of the new diamond tools. MMC are alloys composed of a matrix metal and dispersed reinforcing particles or whiskers e.g. aluminium foundry alloys reinforced with silicon carbide or with aluminium oxide. The unique combination of low weight with high strength and wear resistance is a highly desired property in the automotive and aircraft industries. The coated tools are superior to PCD tools in turning Al-20\% SiC metal-matrix composites (Bauer 1994).as the binder-free diamond coating is more wear resistant than the sintered PCD blank.

Another potential application of diamond tools is in machining carbon-carbon $(\mathrm{C}-\mathrm{C})$ composites and in the woodworking industry. A tailor-made shape of the coated tool (e.g. helical end mills for $\mathrm{C}-\mathrm{C}$ machining or complex special profiles for wood shaping) will have a significant advantage over the conventional WC-Co tools (in performance) and over specially designed PCD tools (in price).

\subsection{PCBN tools}

Despite the increased use of aluminium-silicon alloys, grey cast iron is still the most abundant material in the heavy and automotive industries. Machinability of cast iron depends 
primarily on its microstructure but also on the amount of sand in casting, the distribution of chills and on the dimensional variations due to casting swell. PCBN tools are extremely successful in machining grey cast iron, particularly in machining homogeneous pearlitic castings. Machining grey cast iron may become a major application of $\mathrm{cBN}$ coated tools, when available.

PCBN tools are also among the very few tools capable of economically machining powder metal (PM) parts. Some of the listed new uses of PM technology in the automotive industry are the 3.11 V-6 engine at General Motors, as well as new transmissions, pressure plates, sprockets. clutch hubs and turbine hubs at Ford. Hard turning is another expanding application of PCBN tools, which involves cutting steel with a Rockwell hardness of C-45 or above. At present most such parts are finished ground. Hard turning is being introduced to replace many of the present grinding processes. A PCBN tool cost per part is often twice grinding wheel costs, but the cost and maintenance of a grinding machine are generally 2-3 times greater than that of a lathe. Machining also offers faster stock removal, a one-step processing of complex parts and shorter set up time in small runs. The replacement of grinding processes with hard turning machining will affect future demand for PCBN (and cBN coated) tools.

\section{Performance of coated tools}

The coated tool has to perform at a level which is at least equal to the PCD tool but at a much lower cost per insert. Performance of the coated tool is measured by the tool life and by the resultant surface finish of the workpiece. For all practical purposes, performance of a coated tool is determined by:

- adhesion of the diamond layer: to permit a predictable mode of failure of the tool, i.e. abrasive wear rather than flaking;

- properties of the tool: i.e. wear resistance, micro-hardness, edge coverage. and thickness uniformity of the coated tool;

- acceptable workpiece surface finish, i.e. within the limits set by the end user.

Laboratory and field metal-cutting tests have shown that the performance of diamondcoated WC-Co inserts can be at least equal to that of conventional polycrystalline diamond (PCD). Some specific applications and working conditions are listed as follows:

- machining of fibre reinforced plastics: profiling, turning, facing, and boring at speed $46 / 244 \mathrm{~m} \mathrm{~min}^{-1}$ feeds of $0 \cdot 102 / 0 \cdot 152 \mathrm{~mm} \mathrm{rev}^{-1}$ and depths of $0 \cdot 508 / 1.524 \mathrm{~mm}$ : the coated tool equalled the performance of conventional PCD for the same application;

- turning graphite at $174 \mathrm{~m} \mathrm{~min}^{-1}, 0.127 \mathrm{~mm} \mathrm{rev}^{-1}$, and $6.35 \mathrm{~mm}$ depth: the coated tool outperformed the regular tool for the same application (TiN coated carbide) by a factor of $8-16$;

- machining of $\mathrm{Al}-\mathrm{Si}$ alloy, A380 $(8.5 \% \mathrm{Si}-3.5 \% \mathrm{Cu})$ : facing and interrupted turning at $732 / 826 \mathrm{~m} \mathrm{~min}^{-1}, 0.457 / 0.152 \mathrm{~mm} \mathrm{rev}^{-1}$ and $0.762 / 0.203 \mathrm{~mm}$ depth: some of the coated tools (one edge in each case) outper-formed conventional POD tools by a factor of two;

- machining of Al-Si alloy. A390 (17.0\% Si-4.5Cu-0.6\% Mg): facing, chamfering, and turning at $457 / 488 \mathrm{~m} \mathrm{~min}^{-1}, 0.508 / 0.152 \mathrm{~mm} \mathrm{rev}^{-1}$ and $0.762 / 0.203 \mathrm{~mm}$ depth: the coated tools (one edge in each case) demonstrated an overall performance in the range $69 \%-79 \%$ of a conventional PCD tool in same application. 


\section{In conclusion}

Any new technology has to he evaluated in the context of specific applications. The introduction of the superhard coated tools marks a new era in the utilisation of advanced materials in metal-cutting industry. We have now a better knowledge of the technical requirements for diamond deposition but we are still lacking fundamental understanding of the low pressure deposition of superhard materials. Some of the substantial questions are:

- definition of the mechanism for formation of the coating and identification of principal species in the gas phase and on the coating surface:

- definition and control of the factors that determine the adhesion between the film and the tool substrate:

- the origin of internal stresses in the films and development of new procedures for stress relaxation.

The new technologies will open up new possibilities in tool manufacturing and in machining of advanced materials. Our ability to maximise their potential will be determined by our ability to fully understand the deposition process.

\section{References*}

Anadoh Y, Ogata K, Kamijo F 1988 Nucl. Instrum. Methods 678

Anon 1991 Diamond and structural carbon news. Business Communication Co. Inc., Norwalk, CT

Badzian A R 1988 Phys. Lett. 2495

Bauer C E, Inspector A, Oles O J 1994 Paper presented at ICMCTF-94, April 25-29, San Diego, CA

Chu X, Wong M S, Sproul D, Rohde S L, Barnett S A 1992 J. Vac. Sci. Technol. 10: 1604

Devries R C 1972 Cubic boron nitride. Handbook of properties General Electric Corp. Technical Luf. Ser. Rep. No. 72CRD178

Doll G L, Sell J A, Taylor C A, Carke R 1991 Phys. Rev. B43: 6816

Goranchev B, Schmidt K, Reichelt K 1987 Thin Solid Films : 149

Haubner R, Lux B1993 Diamond Rel. Mater. : 1277

Ikeda T 1992 Appl. Phys. Lett. : 61-786

Ikeda T, Satou T, Satoh H 1991 Surf. Coat. Technol. : 33-50

Inagawa K, Watanabe K, Saitoh K, Yuchi Y, Itoh A 1989 Surf. Coat. Technol. 39/40: 253

Indemitsu 1991 Catalog

Inspektor A, Liou Y, McKenna T, Messier R 1989 Surf. Coat. Technol. 39/40: 211

Jindal P C, Quinto D T, WoIfe G J 1987 Thin Solid Films 154: 361

Kester D J, Messier R 1992 J. Appl. Phys. 72: 505

Kikuchi N, Eto H, Okamura T, Yoshimura H, Tzeng Y, Yoshikawa M, Murukawa M, Feldman A (eds) 1991 Proc. First Int. Conf. on the Application of Diamond Films and Related Materials (New York: Elsevier) p. 61

Kuo C T, Yen T Y, Huang T H 1990 J. Mater. Res. 5: 2515

Lin A Y, Cohen M L 1990 Phys. Rev. B41: 10727

Lux B, Haubner R 1989 Int J. Ref. Met. Hard Mater. 8: 158

Matsumoto S, Sato Y, Kamo M, Sataka N 1982 Jpn. J. Appl. Phys. 21: L183

McCune R C, Chase R E, Drawl W R 1989 Surf. Coat. Technol. 30/40: 223

Mieno M, Yoshida T 1990 Jpn. J. Appl. Phys. 29Ll: 175

Murakawa M, Watanabe S 1990 Surf. Coat. Technol. 43/44: 128

Murukawa M, Takeuchi S, Miyazawa H, Hirose Y 1988 Surf. Coat. Technol. 36: 303

\footnotetext{
*References in this list are not prepared in journal format
} 
Murakawa M, Watanabe S, Miyake S 1991 In New diamond science and technology (eds) R Messier, J T Glass, J Butterler, R Roy (Washington, DC) p. 1099

Nesladek M, Spinnewyn J, Asinari C, Lebout R, Lorent R 1993 Diamond Rel. Mater. 3: 98

Oberg E, Johns F D, Horton H L, Ryffel H H 1992 Machinery handbook 24th edn, (ed.) R E Green (New York: Industrial Press)

Ohtake N, Mashimi Y and Yoshikawa M in Messier R, Glass J T, Butler J E, Roy R (eds) 1991 New diamond science and technology (Washington, DC) p. 173

Rapoport E 1985 Ann. Chim 10: 607

Park B S, Baik Y J, Lee K R, Eun K Y, Kim D H 1993 Diamond Rel. Mater. 2: 910

Saito K, Yagi M, Shibiki K, Takatsu S 1990 Surf. Coat. Technol. 43/44: 30

Saito Y, Sato K, Matsuda S, Koinuma H 1991 J. Mater. Sci. 26: 2937

Saito Y, Isozaki T, Fukumoto A, Chosa M, Ito T, Bauer E, Inspektor A, Oles E J 1993 Diamond Relat. Mater. 2: 1391

Satou M, Fujimoto F 1983 Jpn. Appl. Phys. 22 L171

Shimokawa F, Kuwano H, Nagai K 1985 Proc. 9th. Symp. on ISIAT Tokyo, p. 467

Soderberg S 1990 Vacuum 41: 1317

Soderberg S, Gerendas A, Sjostrand M 1990 Vacuum 41: 2515

Spitsyn BV, Builov L L, Derjaguin BV 1981 J. Cryst. Growth 52: 219

Sueda M, Kobayashi T, Tsukamoto H, Rokkaku T, Morimoto S, Fukaya Y, Yamashita N, Wada T 1993 Thin Solid Films 228: 97

Suzuki H, Matsubara H, Horie N 1986 J. Jpn. Soc. Powder Metall.

Wada T, Yamashita N 1992 J. Vac. Sci. Technol. A10: 515

Yarborough W, Inspektor A, Messier R 1990 In Properties and characterisation of amorphous carbon films (eds) J J Poch, S A Alterovits (Brookfield: VTL Trans. Tech. Publ.) pp 157-174 